\title{
JUSTICE ENHANCES COMMITMENT WHEN COUPLED WITH EMPOWERMENT
}

\author{
Dilawar Khan Durrani \\ Harbin Institute of Technology, P.R. China \\ Xiangyang Li \\ Harbin Institute of Technology, P.R. China \\ Julia Yalalova \\ Harbin Institute of Technology, P.R. China
}

\begin{abstract}
This study explores the impact of organizational justice on employee commitment. It also analyzes the mediating role that psychological empowerment plays in the relationship between organizational justice and empowerment. The sample for this study consisted of 206 respondents from various service sector organizations of Pakistan. The results from the structural equation model analysis revealed that organizational justice was positively related to psychological empowerment and affective commitment. Furthermore, psychological empowerment partially mediated the relation between organizational justice and affective commitment.
\end{abstract}

Keywords: Organizational justice, psychological empowerment, commitment, mediation

\section{JEL code: M100}

Researchers have long argued that in order to have a highly motivated and committed workforce, it is indispensable that an organization should follow fair policies and procedures in the distribution of rewards and resources (Cropanzano, Bowen and Gilliland, 2007). The concept of fairness in organizations is commonly regarded as organizational justice. Many studies have found that the perception of organizational justice leads to favorable employee attitudes and its absence results in undesirable consequences. Such as Bayarçelik and Findikli, (2016) argued organizational justice had a significant impact on turnover intensions and job satisfaction mediated the relationship between organizational justice and turnover intentions. Another study analyzed the mediating role of organizational justice on human resource practices and organizational outcomes and found that desired organizational outcomes were positively related to the perceptions of justice (Zhang and Agarwal, 2009). Many similar studies have reported that organizational justice enhances positive organizational outcomes and mitigates undesired work attitudes (Paolillo et al., 2015; Rabia et al., 2015; Rastgar and Pourebrahimi, 2013; Bidarian and Jafari, 2012) 
Furthermore, another important concept that has been the focus of many researchers is empowerment. Most of the literature related to empowerment revolves around two distinct concepts of empowerment. The first one is termed mostly as organizational empowerment, which refers to organizational structures, practices and policies in order to empower their workforce (Matthews, Diaz and Cole, 2003). The second most studied concept of empowerment in organizational context is termed as psychological empowerment (Spreitzer, 1995). Many studies have found psychological empowerment to be also related to desired organizational objectives such as organizational citizenship behavior (Aksel et al., 2013), employee performance (Yao, Chen and Cai, 2013), organizational learning (Safari et al., 2011) and interpersonal trust (Moye, Henkin and Egley, 2005). One of the most important desired organizational attitudes is employee commitment that leads toward achievement of organizational goals. Though the two concepts of organizational justice and psychological empowerment have been found to be positively related to the concept of affective commitment of employees, however, not many studies have explored the probable mediating role of psychological empowerment in the relationship between organizational justice and employee commitment. This study explores the understudied mediating role of psychological empowerment in the relationship between organizational justice and affective commitment.

\section{Theoretical framework and hypotheses}

\subsection{Justice and psychological empowerment}

Previous researchers have viewed the relationship between organizational justice and psychological empowerment from perspectives that is different from each other. For example one study assessing empowerment of nurses at their work empowerment, argued that organizational justice is a predictor of empowerment (Kuokkanen et al., 2014). Whereas, another study contented that the perceptions of distributive and organizational justice were the consequences psychological empowerment of the workforce (Zhang and Agarwal, 2009). Considering these different perspectives, this study tries to assess the relationship in the context under consideration and proposes that the employees would feel more empowered when they perceived that the management is following fair policies and procedures keeping in view the moral principles of distributive, procedural and interactional justice.

H1: Organizational justice will have a positive effect on psychological empowerment.

\subsection{Psychological empowerment and commitment}

Studies exploring the relationship between psychological empowerment and organizational commitment have found them to be positively related. One such study done by Joo and Shim, (2010) explored the link between psychological empowerment and organizational commitment and analyzed the moderating impact of organizational learning culture on the relationship between these two variables. The study concluded that psychological 
empowerment had a positive relationship with organizational commitment and organizational learning culture significantly moderated the relationship between these two variables. Several other studies also found similar trends regarding the relationship between various forms of empowerment and organizational commitment (Bhatnagar, 2007; Huang et al., 2006; Bogler and Somech, 2004; Janssen , 2004; Avolio, Zhu and Koh, 2004). Considering the findings from previous researches, this study also proposes that psychological empowerment may have a positive impact on organizational commitment in the context under consideration.

H2: Psychological empowerment will positively affect organizational commitment.

\subsection{Justice and commitment (Empowerment as a mediator)}

Studies exploring the relationship between various forms of organizational justice and commitment have often found these two variables to be positively related. A study conducted by Bernerth et al., (2007) found that both distributive and procedural justice was positively related to organizational commitment. Other such studies showing the positive relationship between these two variables were conducted more recently by Paolillo et al., (2015) and formerly by Hassan, (2002). However, so far to the authors knowledge, not many studies have explored the mediating role that psychological empowerment may play in the relationship between various forms of organizational justice and affective commitment of the employees. This study address this proposes the following hypothesis to address the gap in the existing literature:

H3: Psychological empowerment will mediate the positive relationship between the perceptions of organizational justice and affective commitment of employees.

\section{Methodology}

\subsection{Sample}

Judgement sampling was used in order to collect data from 206 respondents working in the service sector of Pakistan. The sample consisted of $61.7 \%$ male respondents and $37.9 \%$ female respondents. Out of the 206 respondents $16 \%$ had attended high school, $53.4 \%$ had completed their bachelor degree, $29.1 \%$ were master degree holders and 1.5\% were Ph.D. scholars. The ages of the respondents were distributed as $34.5 \%$ between 20 to 30 years old, the majority of $44.2 \%$ were 31 to 40 years old, $14.6 \%$ were in their $40 \mathrm{~s}$ and $6.8 \%$ were above 50 years old. Most of the respondents were in their mid-career and had worked in their current position from 5 to 10 years.

\subsection{Measures}

The scale, developed by Niehoff and Moorman (1993) based on the prior work of Moorman 
(1991), was considered to be most appropriate for the data collection of the current study. The scale a total of three dimensions of organizational justice termed as distribute, procedural and interactional justice. Following are the sample items from the measurement instrument "Overall, the rewards I received here are quite fair" (distributive justice), "To make job decisions, my general manager collects accurate and complete information." (formal procedures) and " 3 . When decisions are made about my job, the manager is sensitive to my personal needs" (Interactional justice).

The scale developed by Menon, S. T. (Menon, 1999) was considered to be the most appropriate one in order to measure psychological empowerment in the context under consideration. The scale measured three dimensions of psychological empowerment termed as goal internalization, perceived control and perceived competence. The sample items from the questionnaire are "I am enthusiastic about working toward the organization's objectives" (goal internalization), "can influence decisions taken in my department" (perceived control) and "I have the skills and abilities to do my job well" (perceived competence).

We adapted scale developed by Allen and Meyer (1990) to measure the affective commitment of employees. Since this study focused on only affective commitment of employees therefore only six items were used in the questionnaire. The sample statements used for this study are "I feel emotionally attached to this organization" and "I really feel as if this organization's problems are my own”.

\subsection{Validity and Reliability}

In order to analyze the goodness of fit for the measurement model, second order confirmatory factor was used. The confirmatory factor analysis showed good model fit for the measurement model as depicted by comparative fit index $(\mathrm{CFI})=.97$, goodness of fit (GFI) $=.81$ Tucker Lewis index $(\mathrm{TLI})=.97$ and normed fit index $(\mathrm{NFI})=.90$. The correlations among the variables and the reliability and validity measures are given in table 1 . The composite reliabilities for all the measures were above .92 showing high level of reliability. The average variance extracted for all the variables were above .63 showing high level of convergent validity. Finally, the maximum shared variance was less than average variance extracted for all the measure showing high degree of discriminant validity. The correlations among the variables were less than the square root of average variance extracted further establishing the discriminant validity. 
Table 1. Correlations, validity and reliability measures

\begin{tabular}{|c|c|c|c|c|c|c|}
\hline Variables & $\begin{array}{l}\text { Composite } \\
\text { reliability }\end{array}$ & $\begin{array}{l}\text { Average } \\
\text { variance } \\
\text { extracted }\end{array}$ & $\begin{array}{c}\text { Maximum } \\
\text { shared } \\
\text { variance }\end{array}$ & $\begin{array}{c}\text { Affective } \\
\text { commitment }\end{array}$ & $\begin{array}{l}\text { Psychological } \\
\text { empowerment }\end{array}$ & $\begin{array}{l}\text { Organizational } \\
\text { justice }\end{array}$ \\
\hline $\begin{array}{l}\text { Affective } \\
\text { Commitment }\end{array}$ & 0.957 & 0.634 & 0.570 & 0.796 & & \\
\hline $\begin{array}{l}\text { Psychological } \\
\text { empowerment }\end{array}$ & 0.987 & 0.961 & 0.570 & $0.755^{* *}$ & 0.980 & \\
\hline $\begin{array}{l}\text { Organizational } \\
\text { justice }\end{array}$ & 0.924 & 0.803 & 0.432 & $0.609^{* *}$ & $0.657^{* *}$ & 0.896 \\
\hline
\end{tabular}

Note. The square roots of average variance extracted are given in bold figures diagonally. p $<.01$.

\section{Results}

\subsection{Direct Relationship}

The results from the structural equation model analysis are given in figure 1 . The results revealed that organizational justice had a significant impact on psychological empowerment $(\beta=.66, p<.01)$ supporting hypothesis 1 . The results further showed that psychological empowerment also had a significant impact on affective commitment of the employees $(\beta$ $=.63, p<.01)$ thus hypothesis 2 was also accepted. Organizational justice was also found to be positively related to affective commitment $(\beta=.20, p<.01)$. The significance of this path shows that the relationship between these two variable may be partially mediated by psychological empowerment which is explored in the next section.

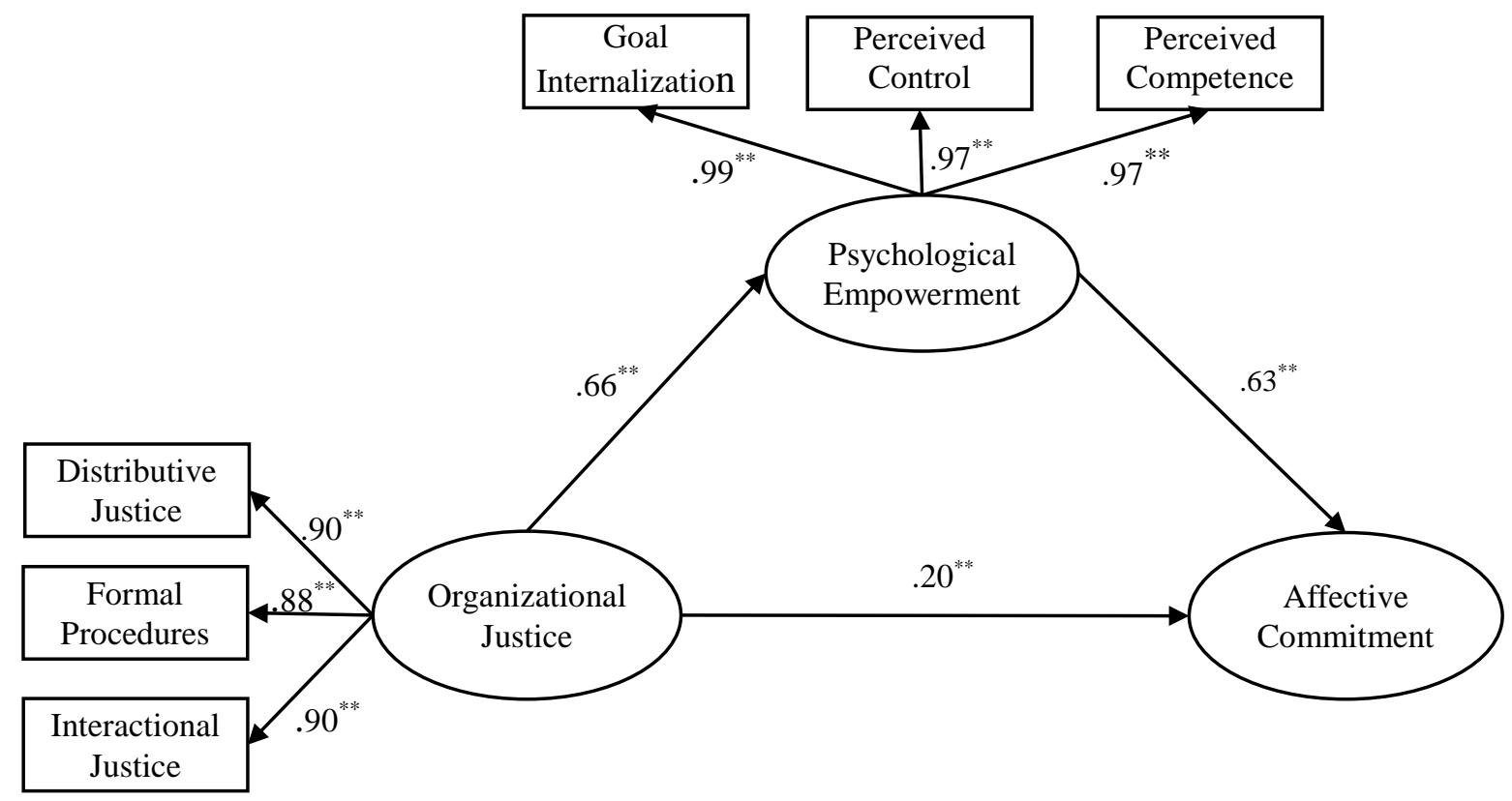

Figure. 1. Standardized path coefficients of the structural model 


\subsection{Mediating effect of empowerment}

We used 3000 bootstrap samples and $95 \%$ bias corrected confidence interval to check for any indirect effect of organizational justice on affective commitment mediated by psychological empowerment. The results showed that organizational justice had a significant indirect effect on affective commitment mediated through psychological empowerment $(\beta=.411, p<.01$, $95 \%$ bias corrected confidence interval [LLCI $=.249$; ULCI $=.602])$. Thus hypothesis 3 was also supported confirming that psychological empowerment mediated the positive relationship between the perceptions of organizational justice and affective commitment of employees.

\section{Discussion and Conclusion}

The results of this study added to the existing literature by empirically analyzing the mediating role that psychological empowerment plays in the previously explored relationship between organizational justice and affective commitment. These results have some useful practical implications for the management of the organizations that are striving to enhance the commitment level of their employees. The results show that in order to effectively reap the benefits of practices that create the perceptions of organizational justice among employees, it is vital that these practices should also be supported by the efforts to empower the workforce so that the potential benefits of justice perceptions can be synergized with psychologically empowered employees to develop a highly committed workforce willing and able to strive hard for the accomplishment of organizational goals. 


\section{References}

Aksel, I. et al. (2013) 'Assessment of Teachers' Perceptions of Organizational Citizenship Behaviors and Psychological Empowerment: An Empirical Analysis in Turkey', Procedia Social and Behavioral Sciences. Elsevier B.V., 89, pp. 69-73. doi: 10.1016/j.sbspro.2013.08.811.

Allen, N. J. and Meyer, J. P. (1990) 'The measurement and antecedents of affective, continuance and normative commitment to the organization', Journal of Occupational Psychology, 63(1), pp. 1-18. doi: 10.1111/j.2044-8325.1990.tb00506.x.

Avolio, B. J., Zhu, W. and Koh, W. (2004) 'Transformational leadership and organizational commitment: mediating role of psychological empowerment and moderating role of structural distance', Journal of Organizational Behavior, 968(May), pp. 951-968. doi: 10.1002/job.283.

Bayarçelik, E. B. and Findikli, M. A. (2016) 'The Mediating Effect of Job Satisfaction On The Relation Between Organizational Justice Perception And Intention To Leave', Procedia Social and Behavioral Sciences. The Author(s), 235(October), pp. 403-411. doi: 10.1016/j.sbspro.2016.11.050.

Bernerth, J. B. et al. (2007) 'Justice, Cynicism, and Commitment: A Study of Important Organizational Change Variables', The Journal of Applied Behavioral Science, 43(3), pp. 303-326. doi: 10.1177/0021886306296602.

Bhatnagar, J. (2007) 'Predictors of organizational commitment in India: strategic HR roles, organizational learning capability and psychological empowerment', The International Journal of Human Resource Management, 18(10), pp. 1782-1811. doi: 10.1080/09585190701570965.

Bidarian, S. and Jafari, P. (2012) 'The relationship between organizational justice and organizational trust', Procedia - Social and Behavioral Sciences. Elsevier B.V., 47, pp. 16221626. doi: 10.1016/j.sbspro.2012.06.873.

Bogler, R. and Somech, A. (2004) 'Influence of teacher empowerment on teachers' organizational commitment, professional commitment and organizational citizenship behavior in schools', Teaching and Teacher Education, 20(3), pp. 277-289. doi: 10.1016/j.tate.2004.02.003.

Cropanzano, R., Bowen, D. E. and Gilliland, S. W. (2007) 'The Management of Organizational Justice', Academy of Management Perspective, (November), pp. 34-49. 
Hassan, A. (2002) 'Organizational Justice As a Determinant of Organizational Commitment and Intention To Leave', Asian Academy of Management Journal, 7(2), pp. 55-66. Available at: http://web.usm.my/aamj/7.2.2002/AAMJ 7-2-4.pdf.

Huang, X. et al. (2006) 'The impact of participative leadership behavior on psychological empowerment and organizational commitment in Chinese state-owned enterprises: The moderating role of organizational tenure', Asia Pacific Journal of Management, 23(3), pp. 345-367. doi: 10.1007/s10490-006-9006-3.

Janssen *, O. (2004) 'The barrier effect of conflict with superiors in the relationship between employee empowerment and organizational commitment', Work \& Stress, 18(March), pp. 56-65. doi: 10.1080/02678370410001690466.

Joo, B.-K. (Brian) and Shim, J. H. (2010) 'Psychological empowerment and organizational commitment: the moderating effect of organizational learning culture', Human Resource Development International, 13(4), pp. 425-441. doi: 10.1080/13678868.2010.501963.

Kuokkanen, L. et al. (2014) 'Does organizational justice predict empowerment? Nurses assess their work environment', Journal of Nursing Scholarship, 46(5), pp. 349-356. doi: 10.1111/jnu.12091.

Matthews, R. a., Diaz, W. M. and Cole, S. G. (2003) 'The organizational empowerment scale', Personnel Review, 32(3), pp. 297-318. doi: 10.1108/00483480310467624.

Menon, S. T. (1999) 'Psychological empowerment: definition, measurement, and validation', Canadian Journal of Behavioural Science, 31(3), pp. 161-164.

Moorman, R. H. (1991) 'Relationship between organizational justice and organizational citizenship behaviors: Do fairness perceptions influence employee citizenship?', Journal of Applied Psychology, 76(6), pp. 845-855. doi: 10.1037/0021-9010.76.6.845.

Moye, M. J., Henkin, A. B. and Egley, R. J. (2005) 'Teacher-principal relationships: Exploring linkages between empowerment and interpersonal trust', Journal of Educational Administration, 43(3), pp. 260-277. doi: 10.1108/09578230510594796.

Niehoff, B. P. and Moorman, R. H. (1993) 'Justice as a Mediator of the Relationship between Methods of Monitoring and Organizational Citizenship Behavior', Academy of Management Journal, 36(3), pp. 527-556. doi: 10.2307/256591.

Paolillo, A. et al. (2015) 'Organizational Justice , Optimism And Commitment To Change', Procedia - Social and Behavioral Sciences. Elsevier B.V., 191, pp. 1697-1701. doi: 10.1016/j.sbspro.2015.04.479. 
Rabia, A. et al. (2015) 'Organizational Justice as a Predictor of Job Satisfaction', Proceedings of 2nd International Conference on Business Management, pp. 1-17.

Rastgar, A. A. and Pourebrahimi, N. (2013) 'A Study of the relationship between organizational justice and turnover intentions : Evidence from Iran', International Journal of Research in Organizational Behavior and Human Resource Management, 1(2), pp. 1-10.

Safari, K. et al. (2011) 'The relationship between psychological empowerment and organizational learning', Procedia - Social and Behavioral Sciences, 30, pp. 1147-1152. doi: 10.1016/j.sbspro.2011.10.224.

Spreitzer, G. M. (1995) 'Psychological empowerment in workplace: dimension, measurement and validation', Academy of Management Journal, 38(5), p. 1442-1465.

Yao, Q., Chen, R. and Cai, G. (2013) 'How internal marketing can cultivate psychological empowerment and enhance employee performance', Social Behavior and Personality, 41(4), pp. 529-538. doi: 10.2224/sbp.2013.41.4.529.

Zhang, H. and Agarwal, N. C. (2009) 'The mediating roles of organizational justice on the relationships between HR practices and workplace outcomes: an investigation in China', The International Journal of Human Resource Management, 20(February), pp. 676-693. doi: 10.1080/09585190802707482. 